\title{
Strategic Alliance Cooperative Partner Selection of Large Complex Projects
}

\author{
Luyun Xue ${ }^{1, a}$, Bin Guo ${ }^{2}$, \\ ${ }^{\mathrm{b}}$ School of Management, Xi'an University of Architecture and Technology, \\ Shaanxi 710055, China \\ bpzlulu@163.com;249640039@qq.com
}

Keywords: complex project, cooperative partners, grey relational analysis.

\begin{abstract}
A large-scale complex project, which has the characteristics of a long time limit, large scale and great investment, needs the cooperation from many parties so that it can be achieved effectively. Selecting cooperative partners scientifically is the point to form a strategic alliance and carry out a project smoothly owing to the complexity and particularity of the large-scale complex project.This paper puts forward the evaluation index system for cooperative partners in strategic alliance of large-scale complex project, and establishes the grey relational model based on the combined weight by using the information entropy and AHP method.
\end{abstract}

\section{Introduction}

In view of the strategic alliance and project evaluation and selection of partner importance to the success of the project, research on strategic alliance and project partners has become the focus of theory and practice, many experts and scholars on the positive discussion, has made a lot of research results, studied the strategic alliance performance measure mainly can be divided into two categories, category method is through some index calculation, on the one hand is the strategic alliance performance ${ }^{[1]}$ finally, on the other hand investigation focuses on the performance of alliance operation process ${ }^{[2-4]}$. Research on the choice of project partners are mainly concentrated in two aspects: one is the construction of evaluation index, which focus on from the perspective of the degree of cooperation project partners to establish evaluation index system ${ }^{[5]}$, such as cooperation intention, cooperation, quality, efficiency, etc., from the perspective of the ability of the project partners on ${ }^{[6]}$ to establish the evaluation index system, such as the ability to project implementation, project quality, management ability, etc.; the other is the choice of evaluation method and model, the current scholars try different quantitative methods to establish the evaluation model, fuzzy comprehensive evaluation model is established with fuzzy mathematics ${ }^{[7][8]}$, the rough set model, multi-objective group decision iterative algorithm ${ }^{[9]}$, etc. This article will large complex project strategic alliance partner selection process as a information has the characteristics of gray, complex multi-factor dynamic comprehensive decision-making process, first of all, build the evaluation index system, build based on AHP and entropy performance evaluation model of grey correlation degree, according to the specific instance application analysis to ensure the objectivity of the selection process, scientific and practical.

\section{Large complex project evaluation index system of strategic alliance partners}

Large complex project as a complex system, construct the evaluation index system should follow the systemic and gradation, the scientific nature and rationality, simplicity and practicality, the principle of combining qualitative and quantitative, considering the above evaluation principle, on the basis of the study of the literature, through the expert investigation and the index system of screening, ultimately determine the large complex project evaluation index system of strategic alliance partners as shown in figure 1. Large complex project evaluation index system respectively from the enterprise strategic alliance partners, projects and enterprises on three levels: foreign relations, including 11 secondary indexes, including qualitative indexes and quantitative indexes, 
fully considering the index number and umbrella, reduce the cross between indicators, a comprehensive measure of potential partners as far as possible the business level and ability to cooperate.

\section{Gray relational assessment model based on combination weighting of information entropy and analytic hierarchy process}

\section{Apply entropy evaluation method to determine the weight}

Considering that the evaluation system has m potential evaluation objects (partners), represented as $\mathrm{Q}=(\mathrm{q} 1, \mathrm{q} 2, \ldots, \mathrm{qm})$.The index system includes $\mathrm{n}$ evaluation indexes, represented as $\mathrm{P}=(\mathrm{p} 1, \mathrm{p} 2, \ldots, \mathrm{pn})$, thus get the initial evaluation matrix $\mathrm{Aij}=($ aij $) \mathrm{m} \times \mathrm{n}$, aij being the evaluation value of $\mathrm{i}$ evaluation object on $\mathrm{j}$ index. In order to eliminate the dimension influence on decision matrix, conduct normalization processing on the efficiency index and cost index of the initial matrix respectively according to the following two formulas, getting normalized matrix:Xij= $(x i j) m \times n$, $i=1,2, \ldots, m ; j=1,2, \ldots, n$.

$$
\begin{gathered}
x_{i j}=\frac{a_{i j}-\min _{j} a_{i j}}{\max _{j} a_{i j}-\min _{j} a_{i j}} \\
x_{i j}=\frac{\max _{j} a_{i j}-a_{i j}}{\max _{j} a_{i j}-\min _{j} a_{i j}}
\end{gathered}
$$

Entropy value $\mathrm{Hj}$ of evaluation index $\mathrm{Pj}$ :

$$
H_{j}=-k \sum_{i=1}^{m} e_{i j} \ln e_{i j}
$$

In the above formula, $\mathrm{Hj}>0$, and it's ruled that when eij=0, eij $\ln$ eij=0

The difference degree coefficient of evaluation index pij. For a given $\mathrm{j}$, the smaller the difference between xij, the larger the entropy value $\mathrm{H}_{\mathrm{i}}$ is, the smaller the function of index $\mathrm{p}_{j}$ is; When the difference between $\mathrm{x}_{\mathrm{ij}}$ is larger and $\mathrm{H}_{\mathrm{i}}$ is smaller, index $\mathrm{p}_{j}$ would have bigger function; the difference degree coefficient $d_{i}$ of evaluation index $p_{j}$ is:

$$
d_{j}=1-H_{j}
$$

The objective weight $\mathrm{w}_{\mathrm{j}}$ of the evaluation index $\mathrm{p}_{\mathrm{j}}$ based on entropy value is:

$$
w_{j}=\frac{d_{j}}{\sum_{j=1}^{n} d_{j}}=\frac{1-H_{j}}{n-\sum_{j=1}^{n} H_{j}}
$$

The obtained objective weight vector determined by entropy evaluation method is

$W_{k}=\left(w_{k 1}, w_{k 2}, \ldots, w_{k n}\right)^{T}$, among which $0<w_{k j}<1, \sum_{j=1}^{n} w_{k j}=1, j=1,2, \ldots n$.

\section{Apply analytic hierarchy process to determine weight}

As to multi-objective decision making problems, the most commonly used method to determine weight is the analytic hierarchy process. Due to the relatively mature development of the method, next its application steps are briefly combed. (1) Conduct target decomposition according to the general objective of the system and build hierarchical structure; (2) Adopt certain scale method to quantify elements of various layers, constructing judgment matrix; (3) Achieve the characteristics of the judgment matrix. Carry out importance ranking by its corresponding eigenvectors; (4) Conduct consistency check on judgment matrix and judge the rationality of weight distribution. The determined subjective weight vector according to the analytic hierarchy process 
is $W_{z}=\left(w_{z 1}, w_{z 2}, \ldots, w_{z n}\right)^{T}$, among which $0<w_{z j}<1, \sum_{j=1}^{n} w_{z j}=1, \quad j=1,2, \ldots n$.

\section{Gray relational assessment based on combination weighting}

(1) Combination weighting process

The weight determined by entropy value method can transfer data information of attribute value for initial assessment index, with sufficient objectivity. While adopting analytic hierarchy process to determine weight is a kind of subjective weight assignment method, which fully combines people's experience to score and judge the objective phenomenon with expert's opinions. In order to achieve the unification of subjectivity and objectivity, the combination weight vector $W=\left(w_{1}, w_{2}, \ldots, w_{n}\right)^{T}$ is obtained, among which $0<w_{j}<1, \sum_{j=1}^{n} w_{j}=1, j=1,2, \ldots n$. That is, conduct linear combination on

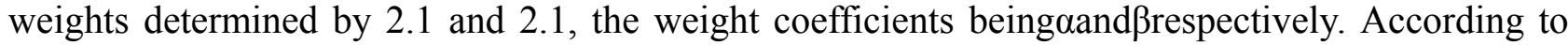
the objective actual circumstance of the partner and cognitive level of experts and scholars, as well as the confident degree of the policy maker, both $\alpha$ and $\beta$ can take different interval values.

$W=\alpha W_{k}+\beta W_{z}$

among which $0 \leq \alpha, \beta \leq 1, \alpha+\beta=1$.

(2) Coefficient calculation of gray relational

The basic idea of grey relational analysis is to determine geometric shape similarity degree between reference sequence and several comparative sequence, in order to judge whether the connection is tight or not. It reflects the relational degree between the curves, namely adopting the degree of association beetween evaluation index sequence and relatively optimal evaluation index sequence as the evaluation criterion of the scheme. Organize the relatively optimal evaluation values in the normalized matrix $X_{i j}=\left(x_{i j}\right)_{m \times n}$ into reference sequence $X^{*}=\left(x_{1}^{*}, x_{2}^{*}, \ldots, x_{n}^{*}\right)$, and $X_{i}=\left(x_{i 1}, x_{i 2}, \ldots, x_{i n}\right)$ is the comparison sequence in the normalized matrix. The relational coefficient of $X^{*}(j)$ and $X_{i}(j)$ is:

$\xi_{i j}=\frac{\min _{i} \min _{j} \Delta_{i}(j)+\rho \max _{i} \max _{j} \Delta_{i}(j)}{\Delta_{i}(j)+\rho \max _{i} \max _{j} \Delta_{i}(j)}$

among which $j=1,2, \ldots, n ; \quad \Delta_{i}(j)=\left|X^{*}(j)-X_{i}(j)\right| ; \rho$ referred to as resolution ratio: the smaller

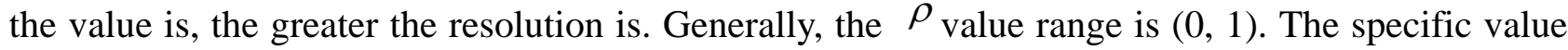
depends on the state.Usually take $\mathrm{p}=0.5$

(3) Grey relational calculation and sorting based on combination weighing

For evaluation system containing $m$ evaluation objects and $n$ evaluation indexes, the relational coefficient matrix $\Pi=\left(\xi_{i j}\right)_{m \times n}$ can be obtained by calculation of the above formula (7). Multiply the relational coefficient matrix II and weight vector $\mathrm{W}$ together and the decision vector $\mathrm{L}$ is obtained, namely,

$L=\left(\ell_{1}, \ell_{2}, \ldots, \ell_{m}\right)=\Pi \times W$

among which $\ell_{i}=\sum_{j=1}^{n} \xi_{i j} w_{j}, i=1,2, \ldots m$.

Conduct sorting according to the value of $\ell_{i}$, if $\ell_{i}>\ell_{i+1}$, the comparison sequence $X_{i}=\left(x_{i 1}, x_{i 2}, \ldots, x_{i n}\right)$ is more similar to reference sequence $X^{*}=\left(x_{1}^{*}, x_{2}^{*}, \ldots, x_{n}^{*}\right)$; then if the value

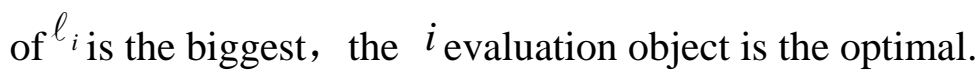




\section{Case analysis}

Now take the construction of the project in some city as an example and adopt the above evaluation index system and evaluation model to study on potential partner selection.

\section{Information of the initial data}

As to some tender construction of the first phase of a project in some city, after the extensive bidding and inspection in the early period, 4 potential contractors are determined. Index 2, 5 or 6 represents the quantitative index and the data is provided by the various potential contractors. The rest indexes are the qualitative indexes. For a certain qualitative index, based on the literature ${ }^{[8]}$, scale the relative virtues or defect degree of various schemes to get the data of qualitative index. Thus the initial data of evaluation index for potential cooperative partners is obtained and shown in Table 1.

Table1 The initial data of evaluation index for potential cooperative partners

\begin{tabular}{lccccc}
\hline No. & $\begin{array}{c}\text { Potential } \\
\text { cooperative partners } \\
\text { Evaluation index }\end{array}$ & $\mathrm{A}$ & $\mathrm{B}$ & $\mathrm{C}$ & $\mathrm{D}$ \\
\hline 1 & $\begin{array}{c}\text { Management ability } \\
\text { Enterprise performance } \\
\text { (output) }\end{array}$ & 0.667 & 1.0 & 0.905 & 0.538 \\
& 426 & 450 & 530 & 348 \\
3 & & & & \\
4 & Innovation capability & 0.743 & 0.818 & 1.0 & 0.538 \\
5 & Executive force & 0.667 & 0.905 & 1.0 & 0.429 \\
6 & $\quad$ Project cost & 6500 & 7000 & 6800 & 7500 \\
7 & Project schedule & 458 & 470 & 425 & 465 \\
8 & Quality controllability & 0.743 & 0.818 & 1.0 & 0.905 \\
& Safety management & 0.538 & 1.0 & 0.818 & 0.429 \\
9 & capability & & & & \\
10 & Cooperative willingness & 0.818 & 0.667 & 1.0 & 0.905 \\
11 & Partner satisfaction & 0.538 & 0.818 & 1.0 & 0.743 \\
\hline
\end{tabular}

Weight calculation for evaluation index

(1)According to the initial data in Table 1, the objective weight of evaluation index is calculated by formula (1) to (5) .

$W_{K}=(0.091,0.084,0.079,0.079,0.075,0.145,0.09,0.103,0.077,0.079,0.097)^{T}$

(2)According to the basic principle of analytic hierarchy process, the subjective weight of evaluation index is calculated by the steps listed in 2.2 (the calculation process is omitted).

$\mathrm{W}_{\mathrm{z}}=(0.065,0.026,0.015,0.07,0.24,0.20,0.09,0.11,0.22,0.09,0.0720)^{\mathrm{T}}$

(3) Take the value of $\alpha$ and $\beta$ in formula (6) to be 0.5 (of course, different values can be taken according to the preference of the policy makers), thus the comprehensive weight of various indexes in the index system can be obtained $\mathrm{W}=(0.078,0.055,0.047,0.075,0.157,0.172,0.090,0.107,0.050,0.084,0.085)^{\mathrm{T}}$

\section{Grey relational evaluation}

The relational coefficient matrix is calculated by formula

$$
\Pi=\left|\begin{array}{lllllllllll}
0.410 & 0.444 & 0.473 & 0.462 & 1.000 & 0.406 & 0.333 & 0.382 & 0.478 & 0.333 & 0.393 \\
1.000 & 0.532 & 0.559 & 0.751 & 0.500 & 0.333 & 0.414 & 1.000 & 0.333 & 0.559 & 1.000 \\
0.708 & 1.000 & 1.000 & 1.000 & 0.625 & 1.000 & 1.000 & 0.611 & 1.000 & 1.000 & 0.637 \\
0.333 & 0.333 & 0.333 & 0.333 & 0.333 & 0.360 & 0.575 & 0.333 & 0.637 & 0.473 & 0.333
\end{array}\right|
$$

Decision vector $L=\Pi \times W=(0.496,0.619,0.820,0.387)^{T}$ is calculated by formula (8).

Thus the preferential order of the four potential partners is C,B, A, D.

\section{Conclusion}

As to the complexity characteristics of large complex projects, the choice of project cooperative 
partners plays a crucial role in the formation of strategic alliance and effective cooperation. Use combination weighing based on information entropy and the analytic hierarchy process to determine the attribute weight. The analytic hierarchy process has been used widely and has been the mainstream subjective weighing method with strong practicality. The objective weighing based on the information entropy principle can reduce the subjective dependence, giving the objective data information into full play. Combining the two methods can greatly improve the scientificity and rationality of weight distribution.

\section{Reference}

[1]Anand B N, Khanna T. Do firms learn to create value: the case of alliances[ J]. Strategic Management Journal, 2000 (21): 295-315.

[2]Lusch R C, Brown J R. Interdependency, contracting, and relational behavior in marketing channels[J]. Journal of Marketing, 1996 (60): 19-38.

[3]Sampson R C. Experience effects and collaborative returns in R\&D alliances[J]. Strategic Management Journal, 2005 (26): 1009-1031.

[4]Hoang H, Kothaermel F T. The effect of general and partner-specific alliance experience on joint R\&D project performance[ J]. Academy of Management Journall, 2005 (48): 332-345

[5] Yan Hongyan, zhang Feilian, Wang yan, et al. Group Decision-making Method for Project Partners Selection[J]. Journal of Railway Science and Engineering, 2011 (2) : 119-122.

[6] Ren Hong, Yan YongGang, Zhou Tao, et al. Evaluation Study on Organization Alliance Partner of Giant Project Based on Cloud Model and Relational Method [J]. Journal of Civil Egineering, 2011 (8) : 147-152.

[7] Liu Shuqing, Han Yahui. Evaluation and Selection Scheme Study on Project Construction Strategic Partner [J]. Chinese Journal of Management Science, 2008 (10) : 89-97.

[8] Gao Peng, Huang Shixiang. Rough Evaluation Model of Virtual Enterprise Partner Selection [J]. Technological Economy, 2006 (4) : 86-87.

[9] Song Bo, Xu Fei. PPP Project Partner Selection Based on Multi-objective Group Decision Iterative Algorithm[J]. Journal of System Management, 2011 (6) : 690-695. 